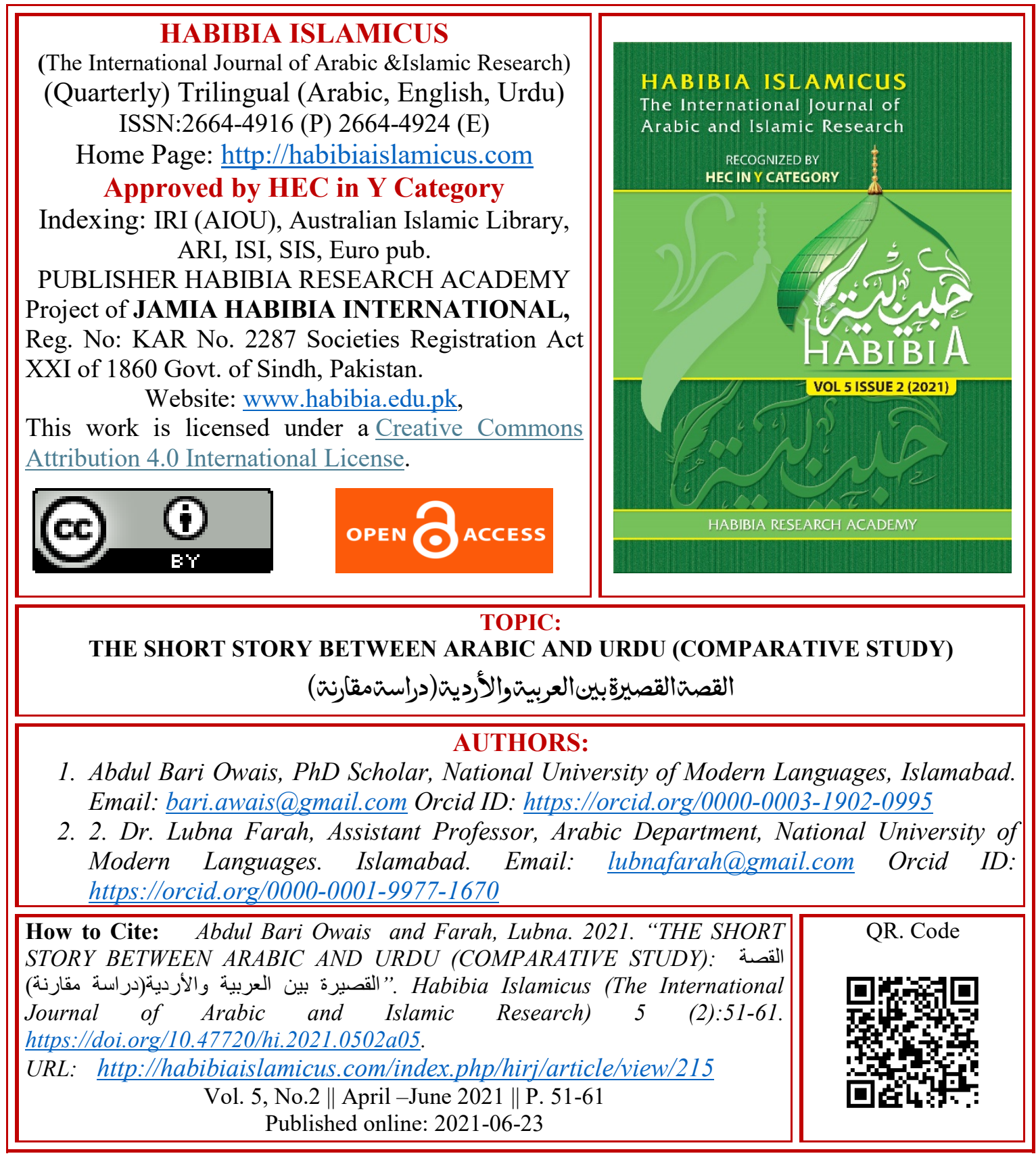


THE SHORT STORY BETWEEN ARABIC AND URDU (COMPARATIVE STUDY) القصتالقصيرة بين العربيتوالأرديت(دراستمقارنت)

Abdul Bari Owais and Lubna Farah

ABSTARCT

This research is an attempt to trace and corelate the evolution of short story in the Arabic and Urdu languages besides highlighting contributions made by the most prominent pioneers and the trends prevailing in different eras of both the languages. The short story is one of the most famous and widely read genres of fiction that seems to answer almost everything near to the nature of human being and whenever it is narrated it feels as if, something exceptional has been created which contains substance of our inferred experience and transitory sense of our common, tempestuous journey of life. Irrespective of the prevailing belief that short story also belongs to the West, its roots in the Arabic language go back to the pre-Islamic times and especially the Golden Age of Islamic civilization which spans from the 8th to the 14th centuries. Anecdotes of the Bedouins and the rhymed Ma'qama were the early foundations of short story in the Arabic language. Then this art reached its epitome in the modern era by the big names like al-Manfaluti, Tawfiq al-Hakim, Naguib Mahfouz, Yahya Haqqi, Ihsan Abdul Quddus, Yusuf Idris and Hasib Kayali. Likewise, the Urdu language that is a product of centuries long interaction between the native Indians and the invading Muslim culture, has borrowed the genre of short story form diverse sources. Then it was matured in the early 20th century by the pioneers like Rashid alKhairi, Sajjad Haider Yaldram, Saadat Hasan Manto, Ahmed Nadeem Qasmi, Mansha Yaad and Intizar Hussain.

KEYWORDS: Short Story, Arabic, Urdu.

مقدمة: وفقاً للخبراء والباحثين، فإنّ طول القصة القصيرة يتراوح ما بين (3-20) صفحة وقراءقا قد تستغرق (15-60)

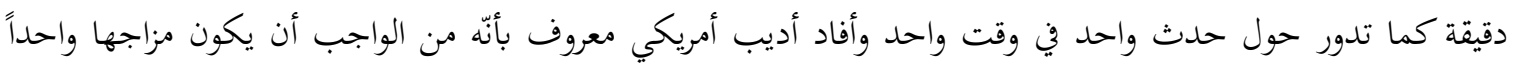

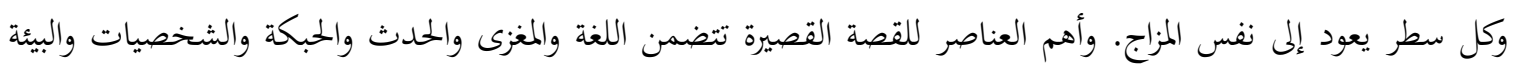
(الزمان والمكان) ولما قيمة بالغة التي تنبع من التعمق والصدق بشأن جميع أنواع الذكريات الإنسانية (الحلوة أو القاسية)

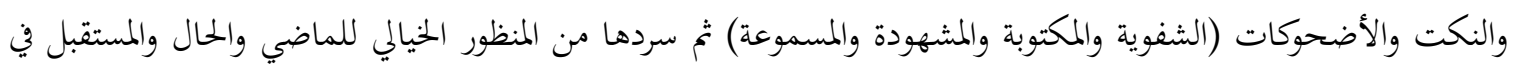

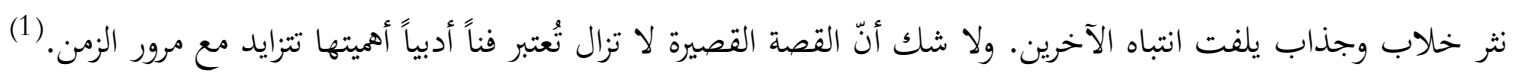

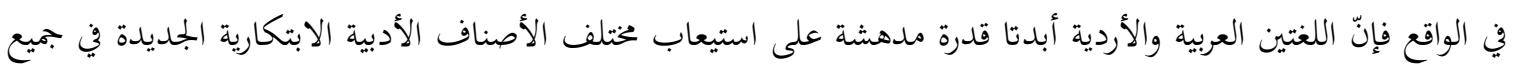

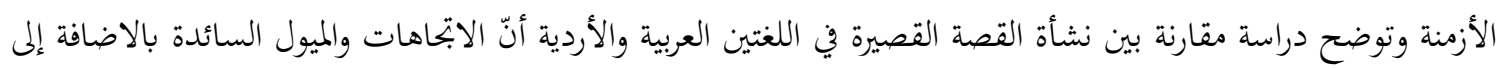

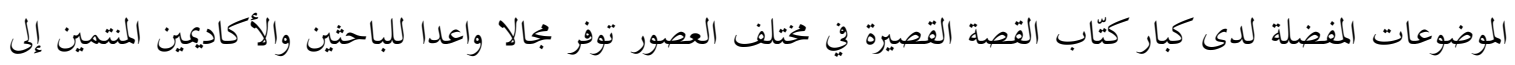

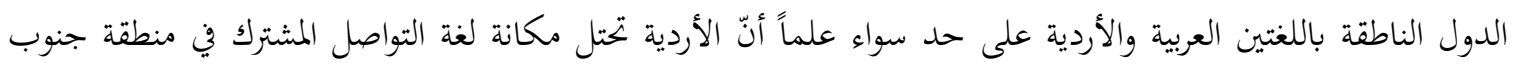

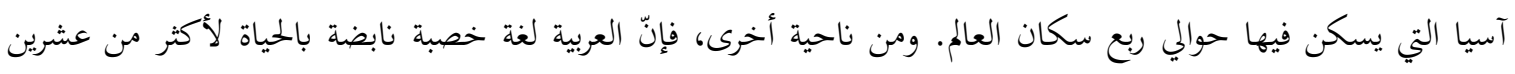

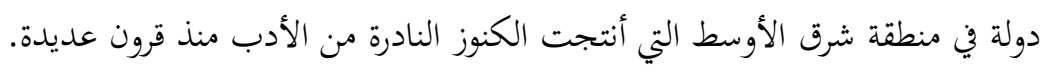




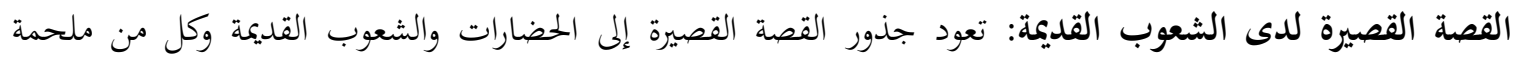

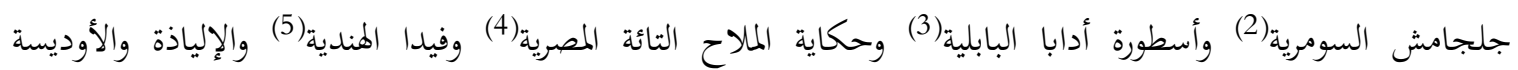
اليونانية(6) تدل على ذلك.

القصة القصيرة والحضارة الغربية: ظهرت القصة القصيية بشكلها الجديد لأول مرة في الولايات المتحدة والأوروبا (لاسيما

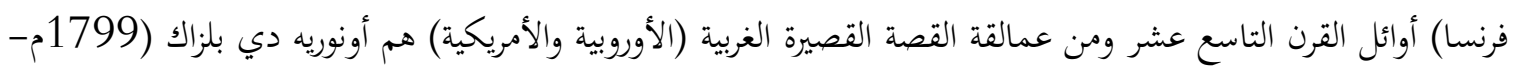

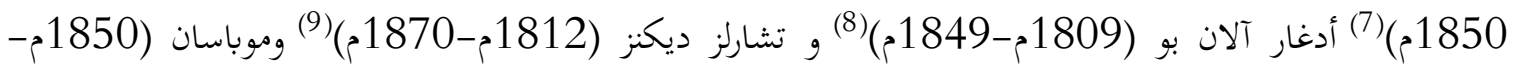

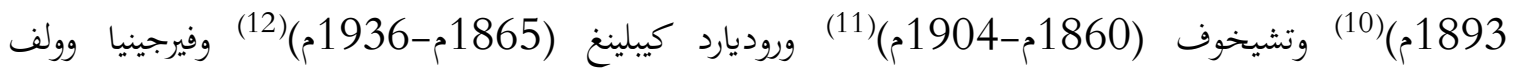

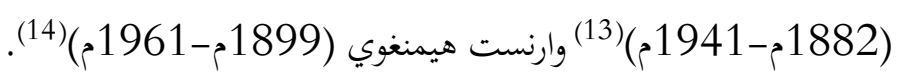

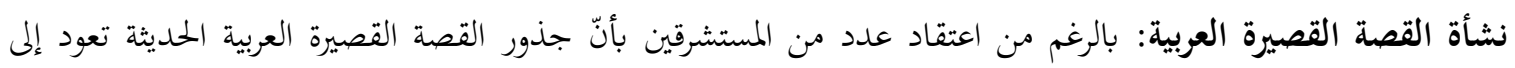

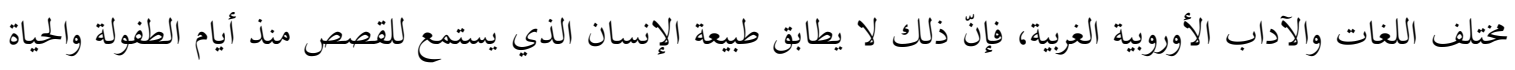

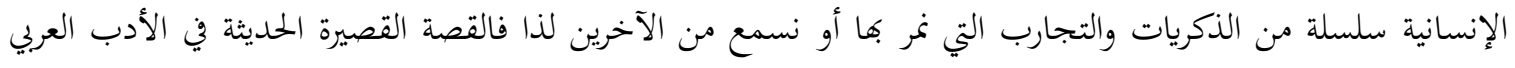

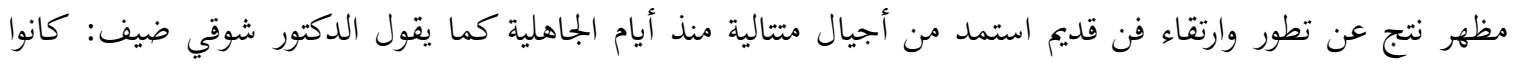
يشغفون بالقصص شغفاً شديداً، وساعدهم على هذا أوقات فراغهم الواسعة في الصحراء، فكانوا حين يُرئخي الليل سدوله

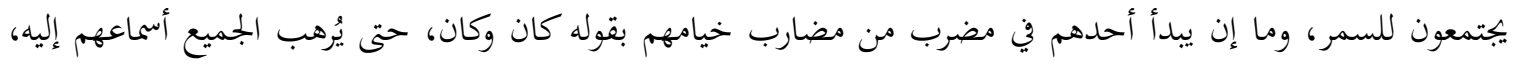

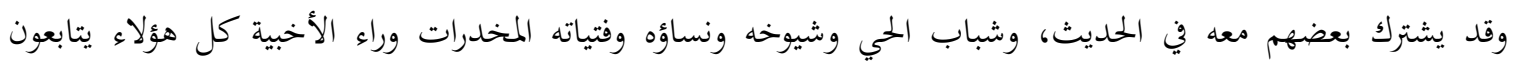

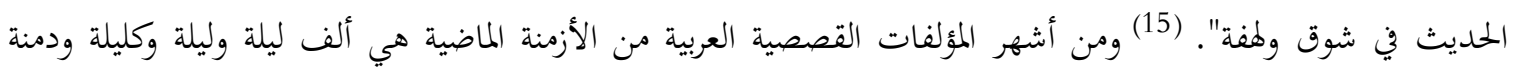

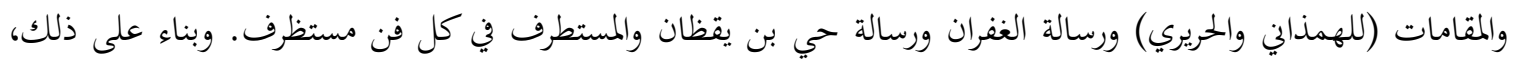

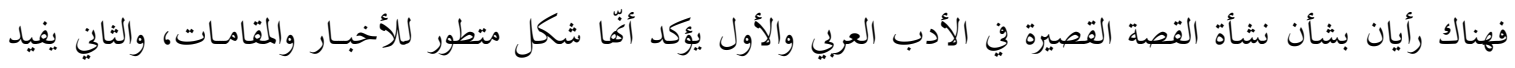

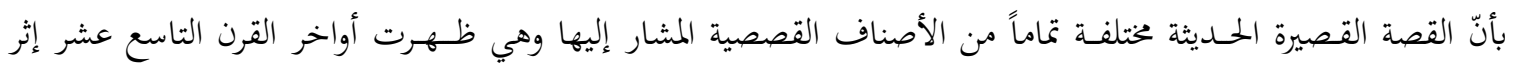

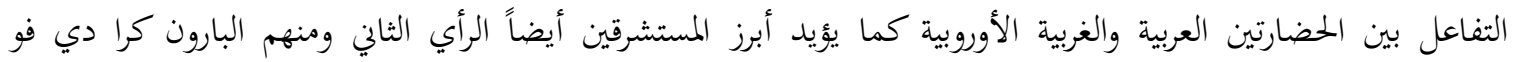
وهاملتون جب. (16) (17) 
ظهور القصة القصيرة في اللغة العربية: ألّف الكاتب العربي الشهير مصطفى المنفلوطي كتاباً بإسم (العبرات) الذي يُعتبر

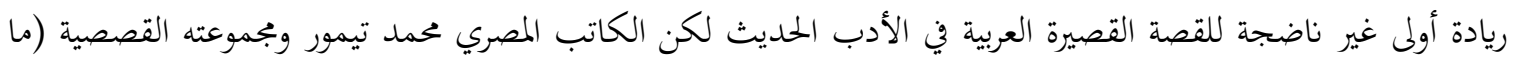

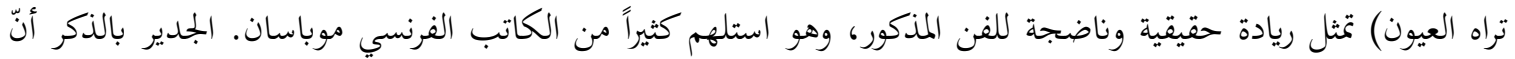

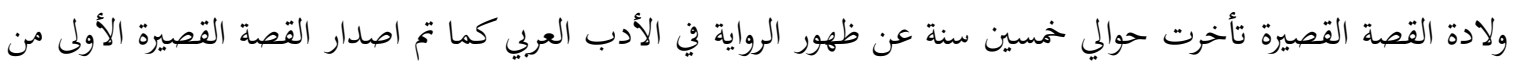
قبل الكاتب المصري (عمد تيمور) في سنة (1917م) وإسهها كانت (في القطار) بينما نشرت الرواية العربية الأولى (زينب)

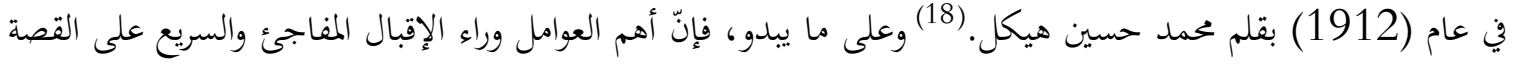
القصيرة في العالم العربي أواخر وأوائل القرنين التاسع عشر والعشرين كانت على النحو التالي: أ- تراث قصصي سردي عميق وغني يمتد إلى القرون. ب- تواصل مع الحضارة الغربية عبر التربمة واستيعاب الأصناف الأدبية الجديدة. تردئ.

$$
\text { ت- اتساع دور الطباعة والصحافة في حياة العرب العامة. }
$$

روّاد القصة القصيرة العربية: ساهم عدد من الكتّاب والأدباء في نشأة القصة القصيرة العربية الذين يمثلون رواداً لما في

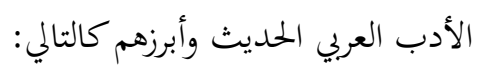

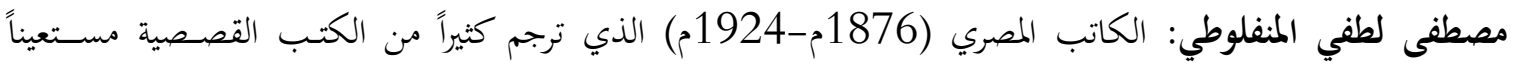
بالأصدقاء متقنين للغة الفرنسية ثم صاغها وصقلها وفقاً للغة والثقافة العربيـة الإسلامية كما يضم كتابه (العبرات)

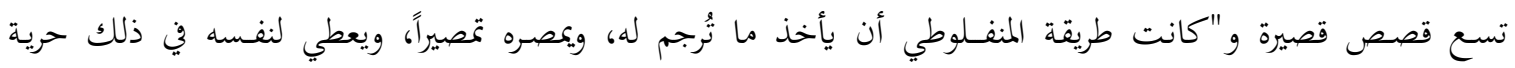
واسعة، حتى لكأنّه يعيد كتابته وتأليفه من جديد، وهو تأليف يقوم على الاسترسال الإنشائي والانطلاق الوجداني والوعظ

الأخلاقي". (19)

محمد تيمور: سبق الذكر أنّ الكاتب المصري محمد تيمور (1892 - 1921م) يُعتبر من مؤسسي القصة القصيرة في الأدب العربي الذي استفاد كثيراً من السفر إلى باريس للدراسة ثم ألّف قصص قصيرة ومسرحيات مستلمهاً من الأدب التبات

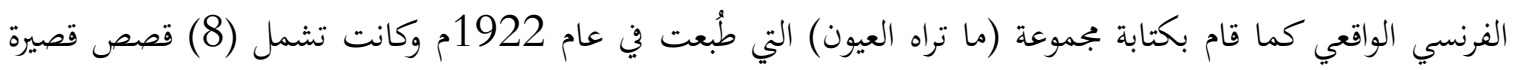

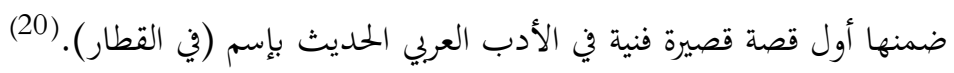

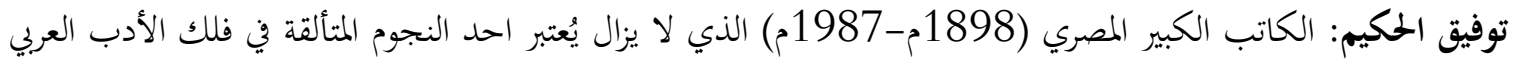

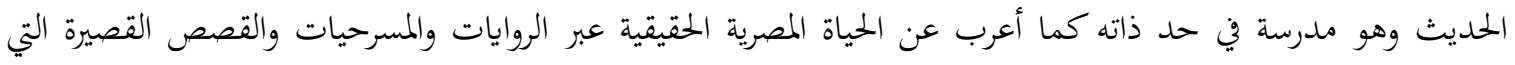

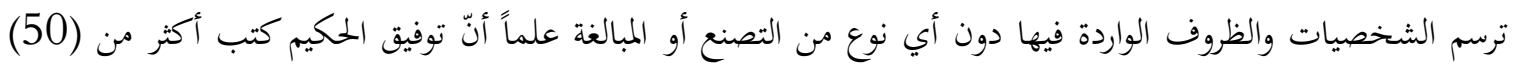

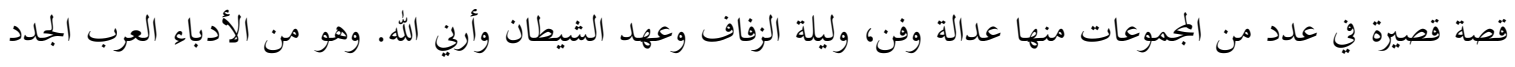


الأكثر غناءً من حيث الفكر والفن اللذان يوجدان في عدد من الأعمال الأدبية التي تدل على مدى الإدراك والدقة وصلابة الرأي ولطافة الشعور . (21)

يييى حقي: الكاتب القصصي والروائي المصري (1905م-1992م) الذي كان محامياً اما أصبح احد الأسماء البارزة في

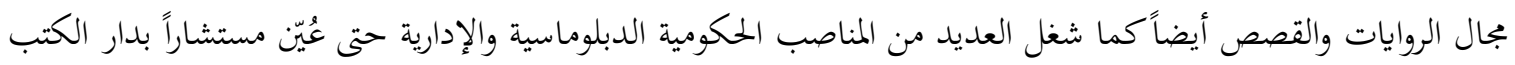

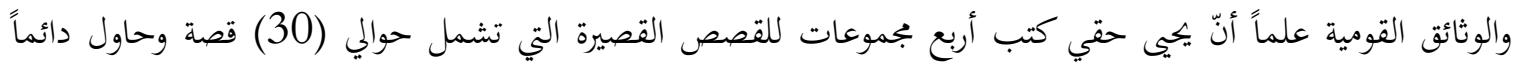

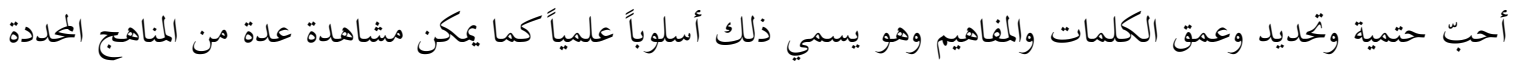

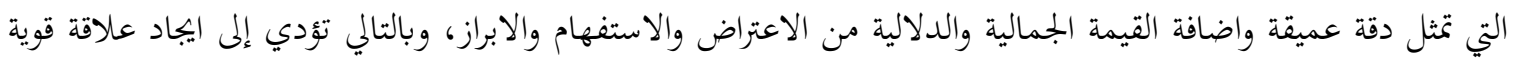
بين النص الظاهري والمعاني المرجوة. (22) نجيب محفوظ: الكاتب الروائي والقصصي الأول في العالم العربي الذي حاز على الجائزة نوبل للآداب وتتميز أعماله بالواقعية

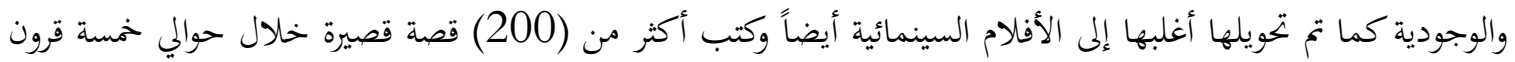

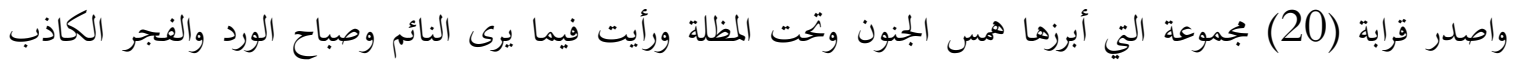
وأصداء السيرة الذاتية وفتوة العطوف وأحلام فترة التفاهة. وتبدو أغلب أعمال نجيب معفوظ الأدبية محاولة رامية إلى ابراز

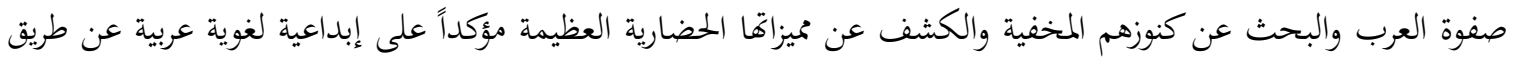

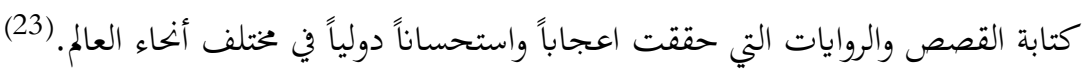
إحسان عبدالقدوس: يُعد إحسان عبدالقدوس (1919م-1990م) احد الأدباء العرب الأوائل الذين تحدثوا عن التئ

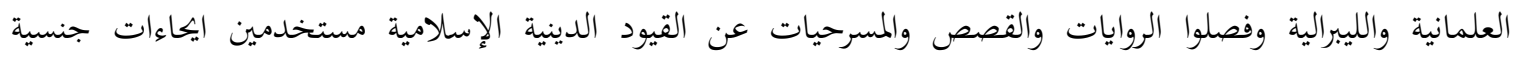

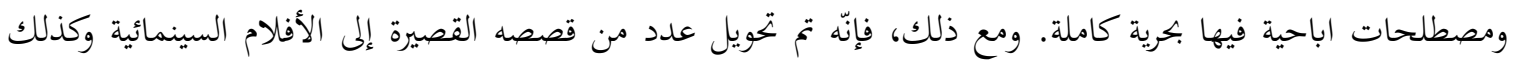
تُرجمت أغلب روايات إحسان عبدالقدوس إلى اللغات الأجنبية(24) كما كتب أكثر من (40) بجموعة للقصص القصيرة

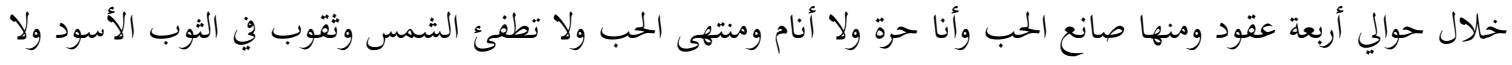

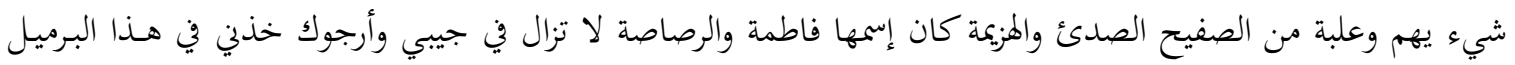

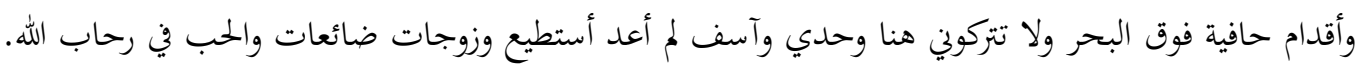

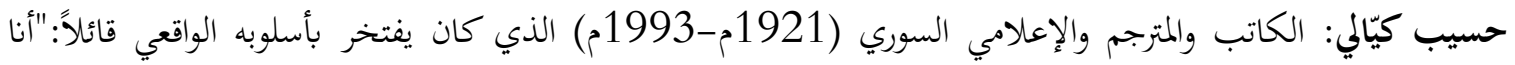

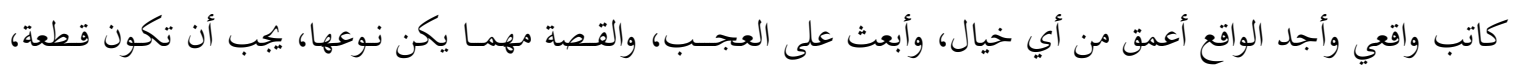

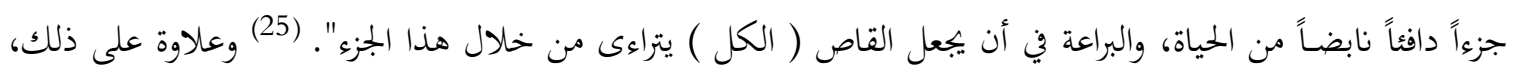

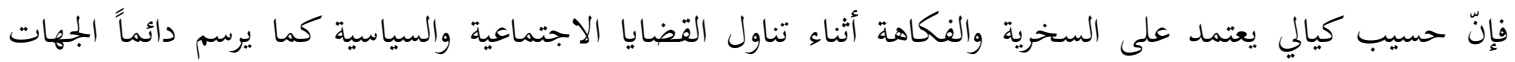

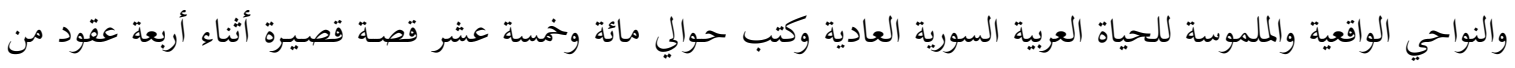


عمره بإصدار (10) مجموعات والتي تتضمن نعيمة زعفران ومن حكايات ابن العم وقصة الأشكال والمطارد والحضور في أكثر من مكان وتلك الأيام وحكاية بسيطة ورحلة جدارية وأخبار من البلد ومع الندات الناس. يوسف إدريس: يُعتبر يوسف إدريس (1927م-1991م) من رواد التجديد في الأدب العربي الحديث الذين تتميز أعماهم

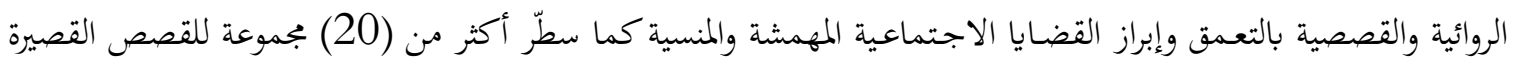

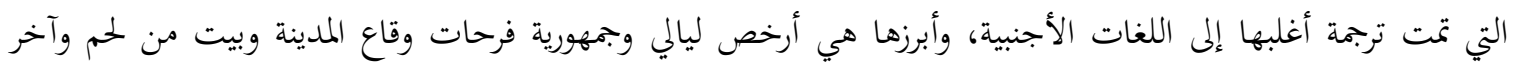

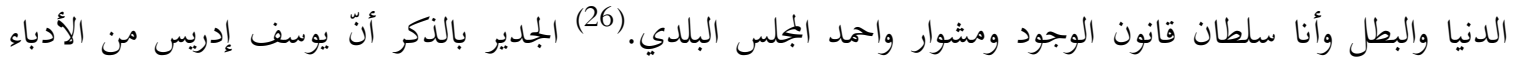

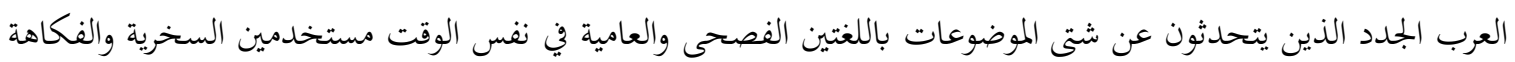

نجيب الكيلاني: الكاتب المصري (1931م-1995م) الذي ذاع صيته بسبب ولوع شديد بالتاريخ الإسلامي كما تناول

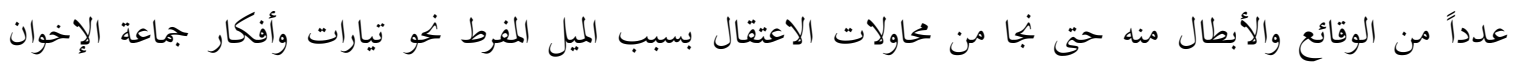

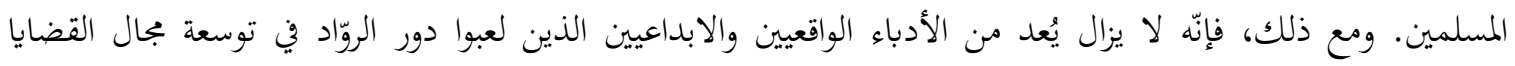

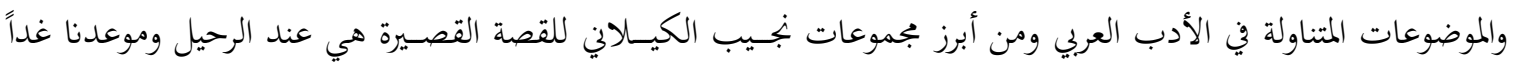

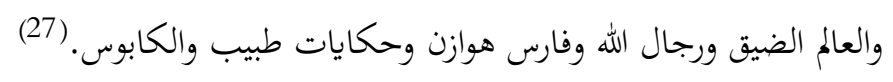

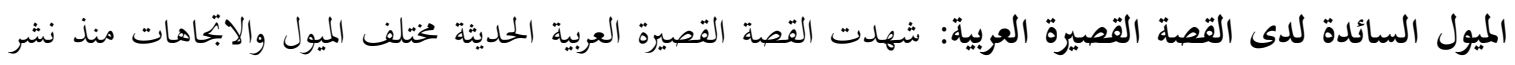

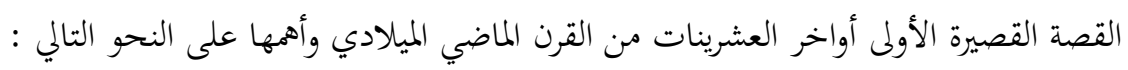
• الوعظ الأخلاقي: ومن أهم مؤيديه لطفي المنفلوطي وتوفيق الحكيم ويوسف إدريس.

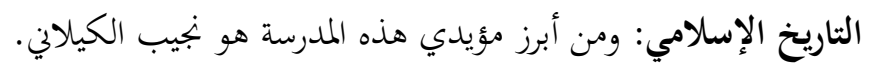

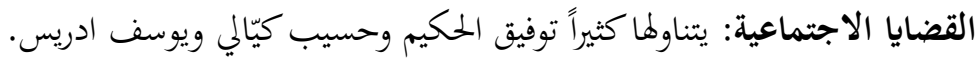

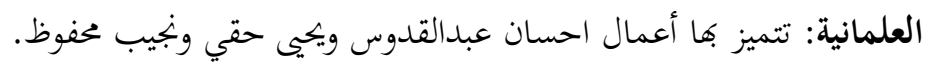
السخرية: يستند إليها حسيب كيّالي ويوسف ادريس ونجيب الكيلاني.

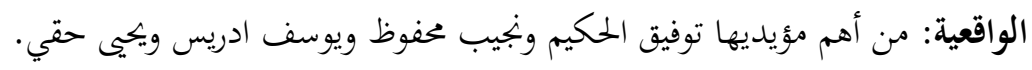

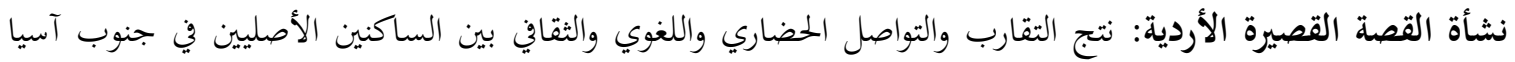

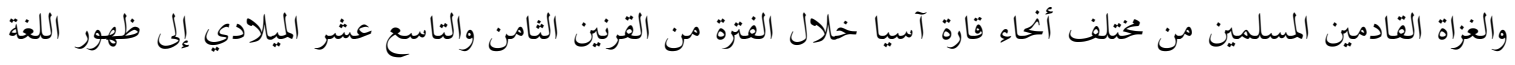

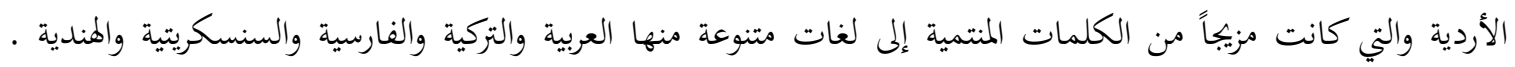

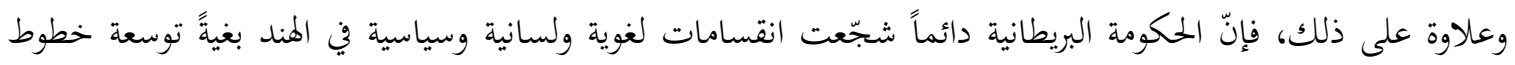

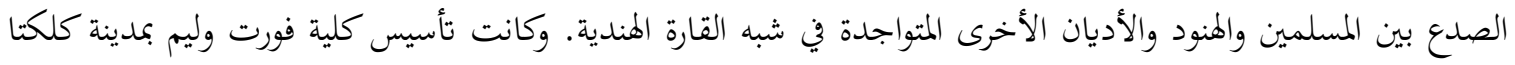


في سنة (1800م) من قبل شركة الهند الشرقية البريطانية أيضاً خطوة بنحو نفس المدف وترويج لغة رسمية جديدة (اللغة

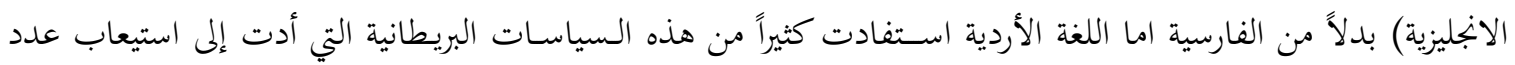
من الأصناف الأدبية الحديثة منها الرواية والقصة القصيرة والمسرحية والمقالة. ولادة القصة القصيرة الأردية الحديثة: تُوجد آراء يختلفة حول ريادة القصة القصيرة الأردية وأولها تعتقد بأنّ الرائد الأول لها

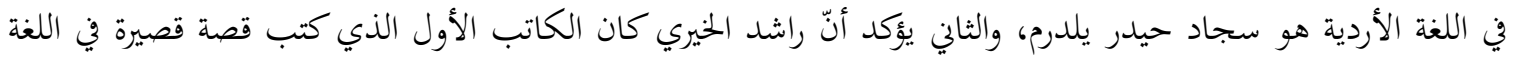

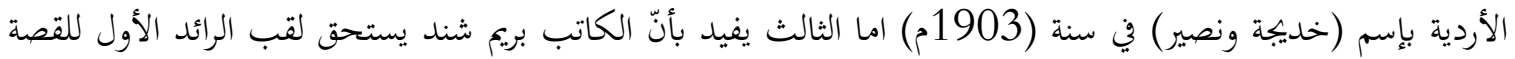
القصيرة في اللغة الأردية.

روّاد القصة القصيرة الأردية: لعب العديد من الأدباء والكتّاب دورهم في تطوير وتعزيز القصة القصيرة للغة الأردية وأبرزهم كالتالي:

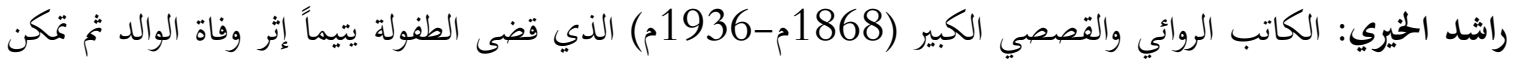
من الحصول على وظيفة حكومية عقب التعليم من المدرسة العربية الواقعة في مدينة دلمي اما استقال من ذلك العمل لكل للتركيز

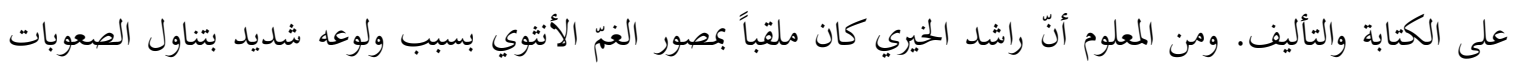

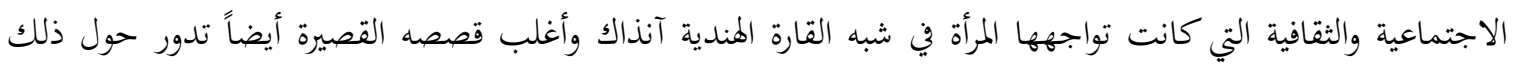

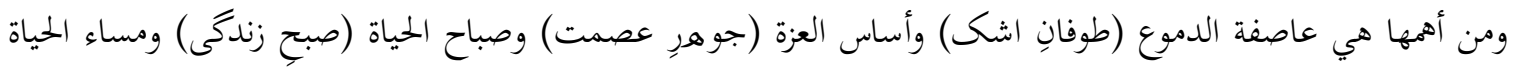

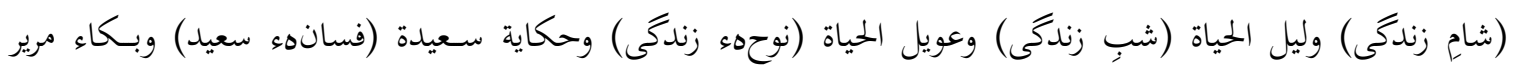

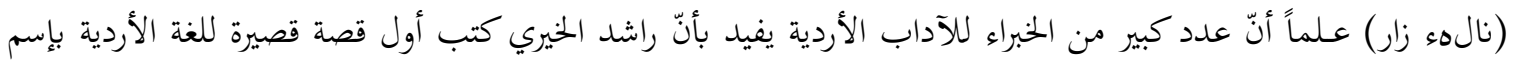

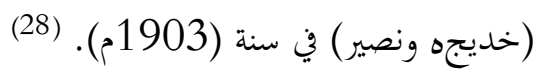

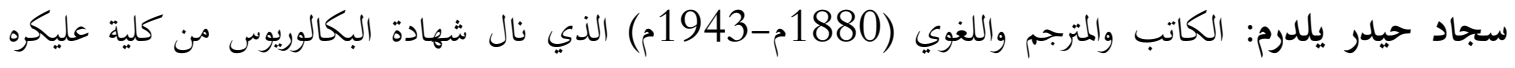
الإسلامية برفقة زملاء مثل مولانا عمد علي جوهر ثماثم حصل على وظيفة المترجم (التركية-الإنجليزية) في البعثة الدبلوماسية

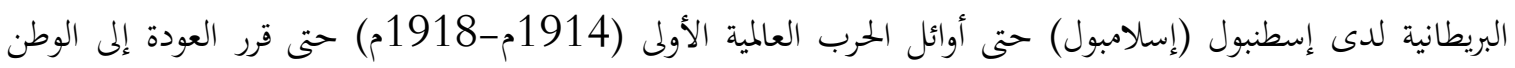

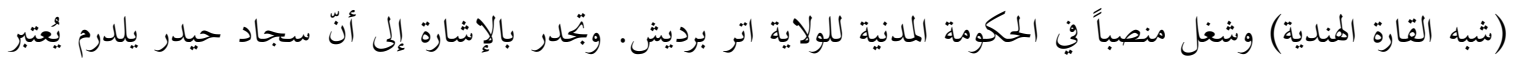

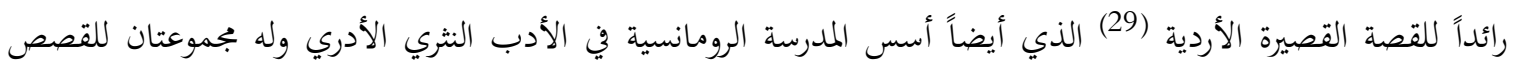

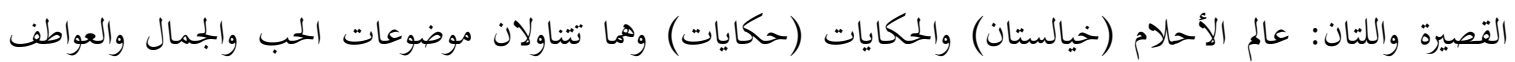
والأحاسيس الإنسانية بالإضافة إلى العقل والواقعية والوجودية والمادية.

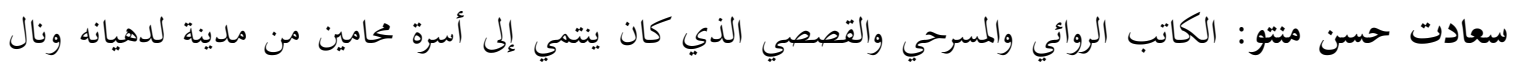

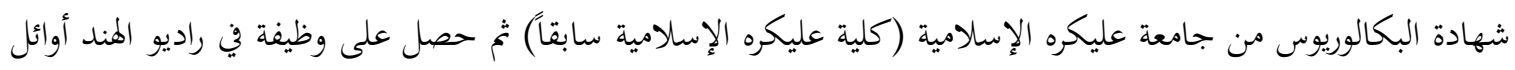


الأربعينات من القرن الماضي اما استقال بسبب الانتقاد على ميوله الأدبية حتى زار مومباي مرة للعمل أيضاً لكنه هاجر

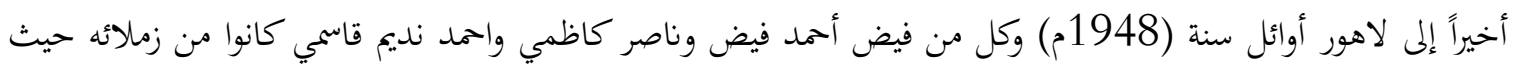

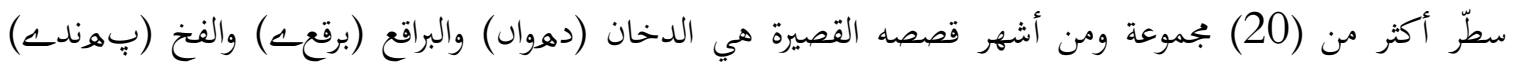

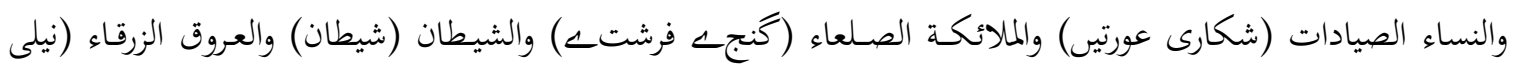

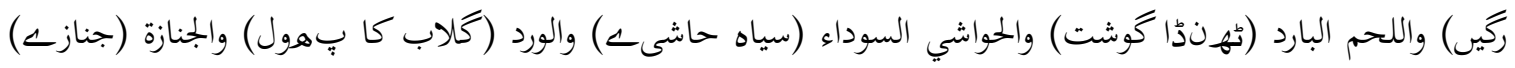

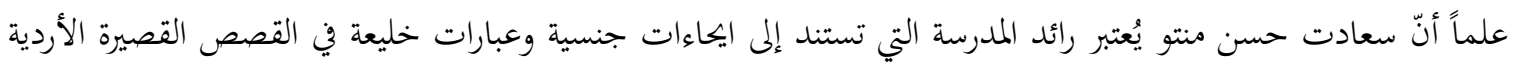

وذلك للتلذذ أو كسب الشهرة الرخيصة. (30)

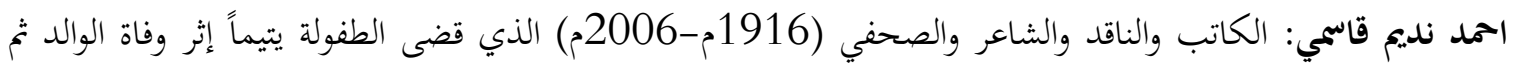

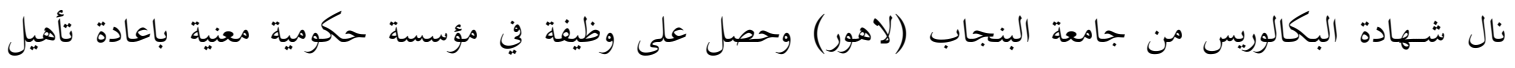

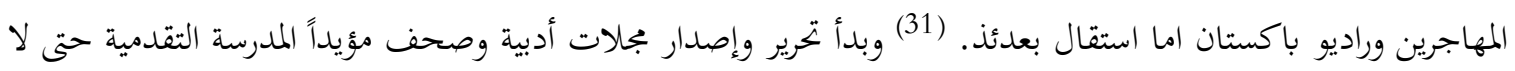

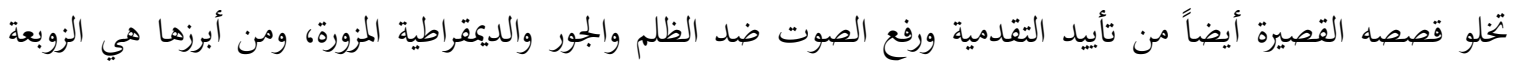

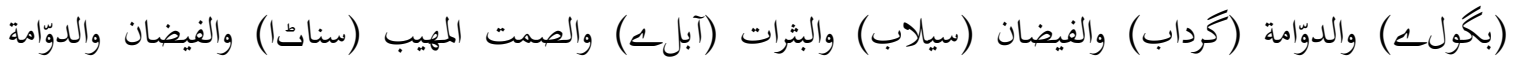

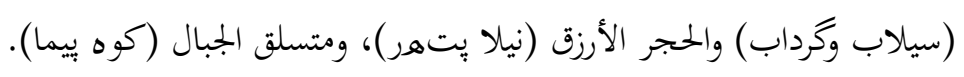

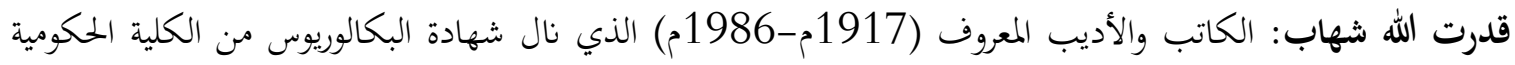

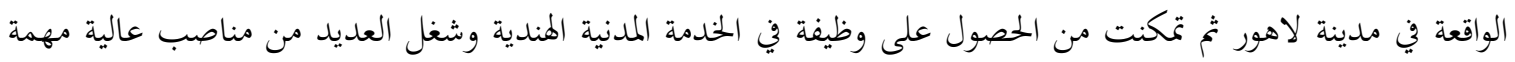

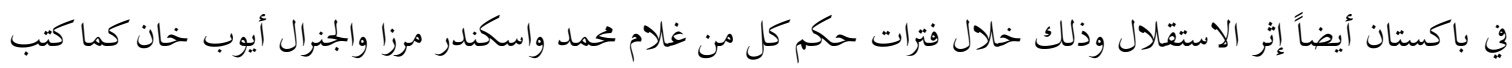

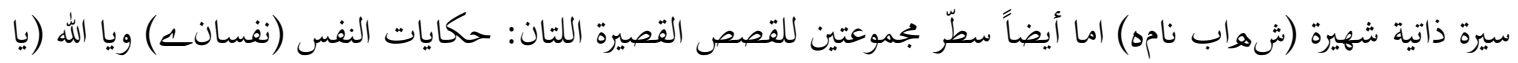
خدا). (32) منشا ياد: الكاتب الروائي القصصي المسرحي والإذاعي (1937م-2011م) الذي كان ينتمي إلى منطقة ريفية واقعة في

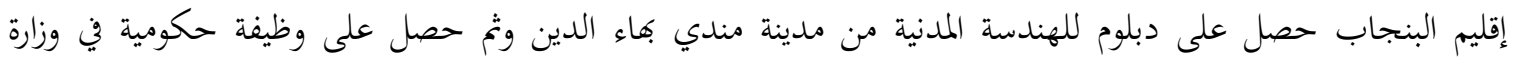

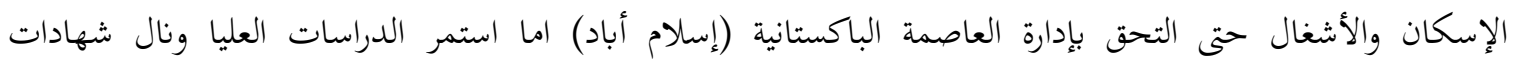

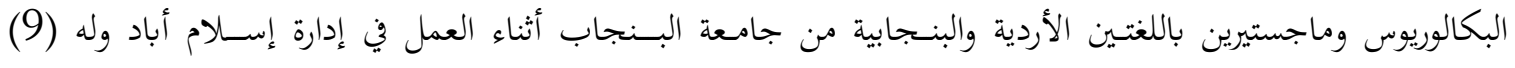

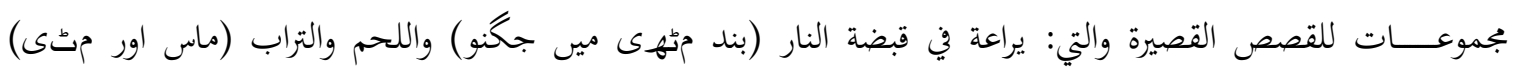

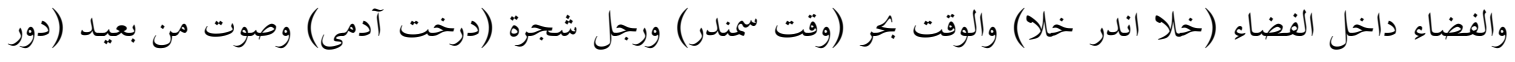

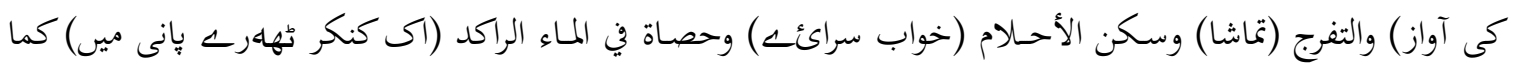


تم منحه عدد من الجوائز ضمنها جائزة (Pride of Performance) تكريماً للخدمات التي قدمها في الجمال الأدبي

والثقافي. (33)

انتظار حسين: الأديب والناقد (1923م-2016م) الذي حصل على شهادة بكالوريوس من كلية ميروت قبل الهجرة إلى

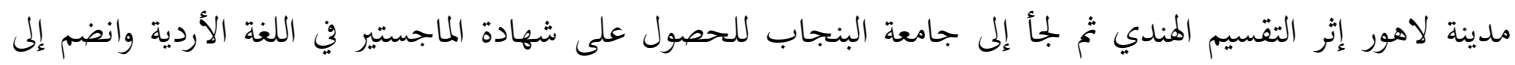

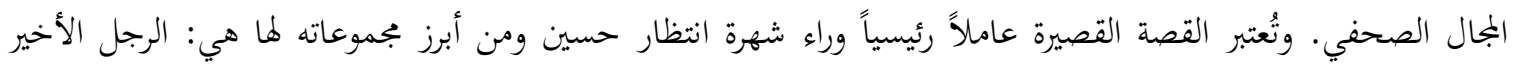

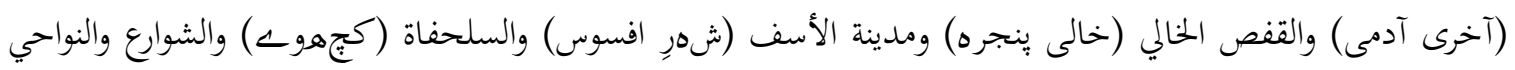

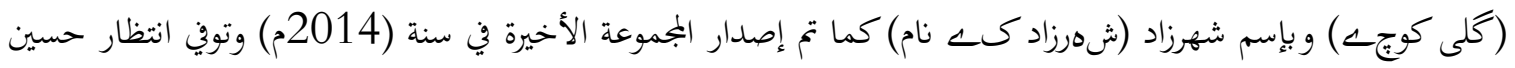

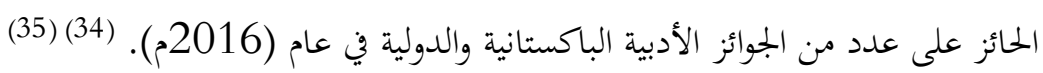

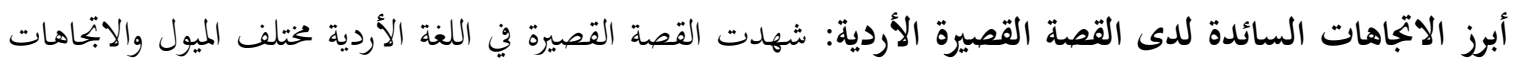

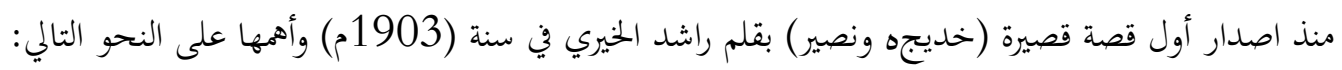

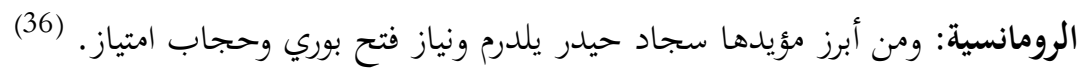
الواقعية: ومن أهم دعاة هذه المدرسة راشد الخيري وبريم شند واحمد علي. (37) الجنسية: وأبرز مشايعيها هم سعادت حسن منتو وعصمت شغتائي. (38)

التقدمية: ومن أهم مؤيدها احمد نديم قاسمي وخديجة مستور ومنشا ياد. (39) الرمزية: ومن أشهر أتباعها انتظار حسين وانور سجاد ورشيد الجحد وحامد بيغ.(40)(41) السخرية: ومن أهم مشايعيها هم شوكت تانوي وشفيق الرحمان ومشتاق احمد يوسفي. (42)(43)(4) الحاتمة: هناك لا شك أنّ القصة من أقدم الفنون النثرية (السماعية والمكتوبة) لدى الإنسان الذي يسمعها منذ الطفولة ويككيها من الشباب إلى الشيخوخة لذا فهي تمكنت من البقاء منذ القرون والأزمنة الماضية والقصة القصيرة نوع فرعي منها التي تقضي جلسة واحدة للقراءة كما سبق الذكر أنّ الأدبين العربي والأردي أيضاً قاما بتطوير القصة القصيرة عقب استيعابها من مختلف المنابع والمصادر الأصلية أو الخارجية وعدد من الروّاد ساهموا في صقلها عبر العصور. فمن محمد تيمور إلى يوسف إدريس ونجيب الكيالاني في الأدب العربي ومن راشد الخيري وسجاد حيدر يلدرم إلى انتظار حسين في الأدب الأردي كلهم لعبوا دورهم الخاص في إغناء وإثراء هذا الفن الثثري الممتع الذي يتلذذ به الصبي والمراهق والشاب والعجوز على حد سواء. 


$$
\begin{aligned}
& \text { (1). الدكتور عز الدين إسماعيل، الأدب وفنونه: دراسة ونقد، دار الفكر العربي، القاهرة، مصر، 2004م، ص:101 } \\
& \text { (2) ) ملحمة مكتوبة بخط مسماري اكتشفت من مكتبة شخصية للملك الآشوري آشوربانيبال في نينوى بالعراق. }
\end{aligned}
$$

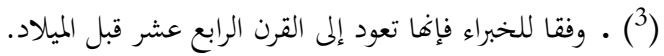

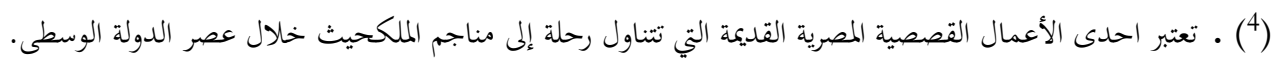

$$
\begin{aligned}
& \text { (5) (5 ) متاب مقدس لدى اتباع الديانة الهندوسية ولها } 800 \text { مجلداً تقريباً }
\end{aligned}
$$

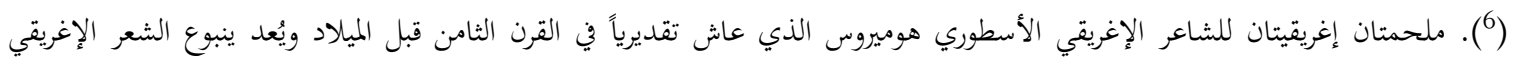

$$
\text { وذروته.(الموسوعة العربية) }
$$

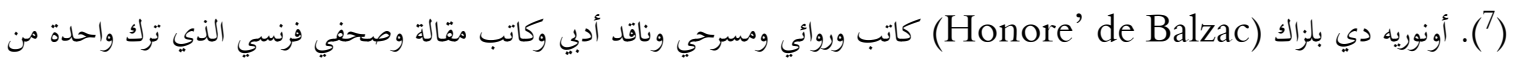

أكثر الكتب الروائية إذهالاً في الأدب الفرنسي مع أكثر من تسعون رواية وقصة قصيرة مُجمعين بعنوان الملهاة الإنسانية. (الموسوعة العربية)

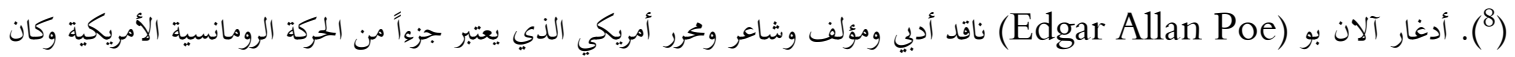

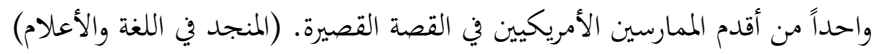

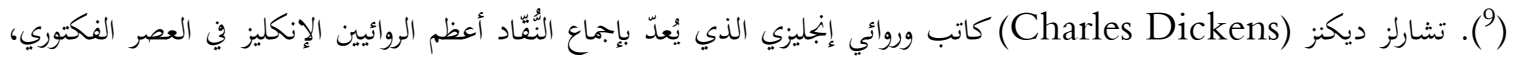

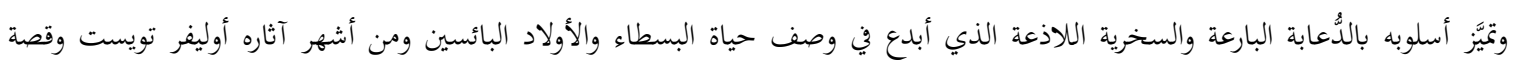

مدينتين ودايفيد كوبرفيلد. (المنجد في اللغة والأعلام)

(10). غي دو موباسان (Guy de Maupassant) كاتب وروائي فرنسي وأحد آباء القصة القصيرة الحديثة الذي يروي العنف اليومي

$$
\text { بأسلوب يراوح مابين الواقع والحيال. (الموسوعة العربية) }
$$

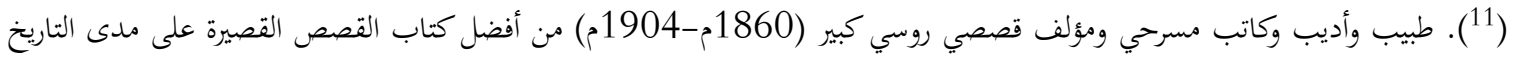

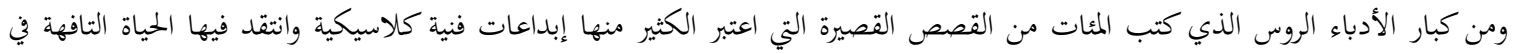

$$
\text { قصور أشراف الروس الريفيين. (المنجد في اللغة والأعلام) }
$$

(2) (12). روديارد كيبلنغ (Rudyard Kipling) كاتب وشاعر وقاص بريطاني ولد في الهند البريطانية، من أهم أعماله كتاب الأدغالالتي مجموعة من القصص حيث ألف العديد من القصص القصيرة منها الرجل الذي اصبح ملكا. (الموسوعة البريطانية)

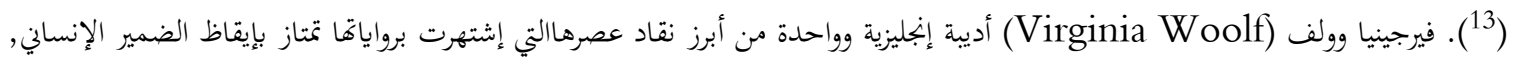
ومنها :السيدة دالواي، والأمواج،. (الموسوعة العربية)

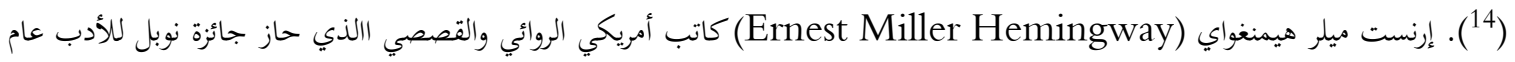
1954م وتميز بأسلوبه البرقي المكثف السريع والواضح والسهولة. (الموسوعة العربية)

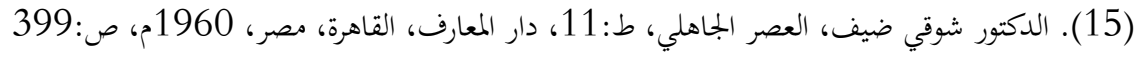

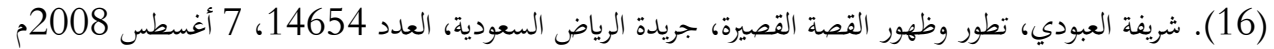

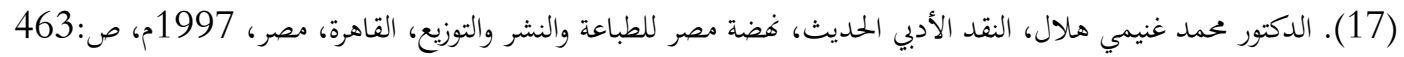


(18). الدكتور امد هيكل، تطور الأدب الحديث في مصر (من أوائل القرن التاسع عشر إلى قيام الحرب الكبرى الثانية)، ط:6، دار المعارف،

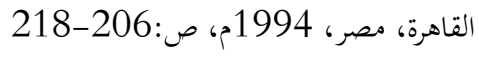

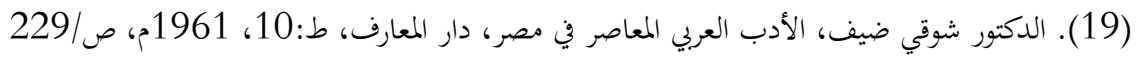

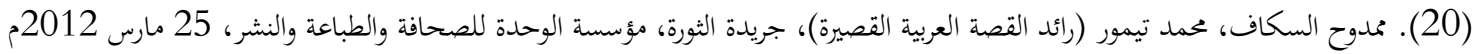

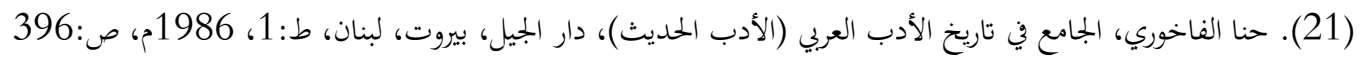

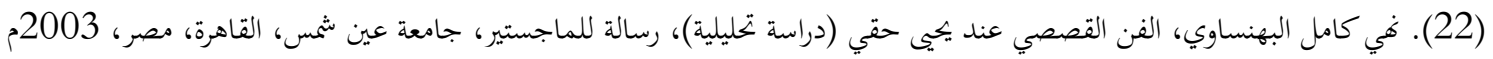

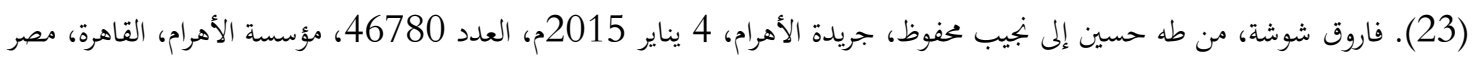

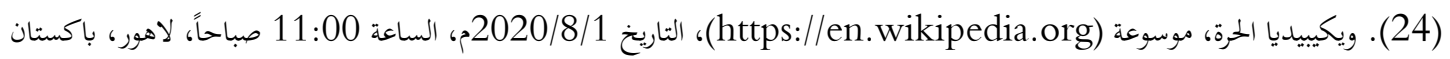

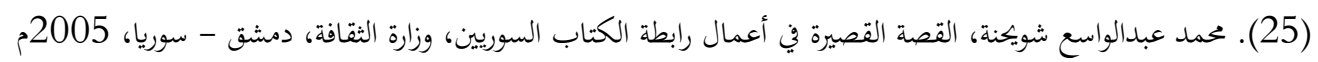

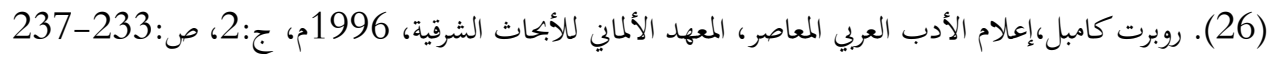

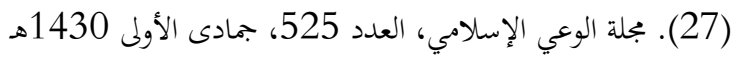

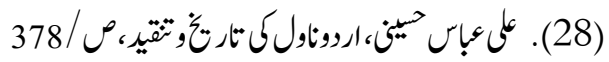

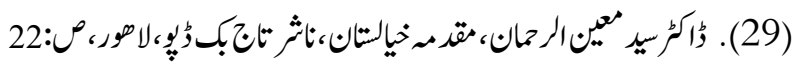

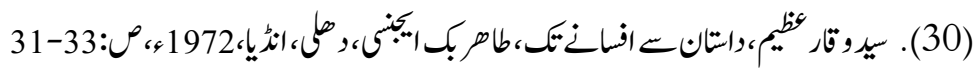

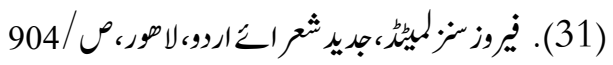

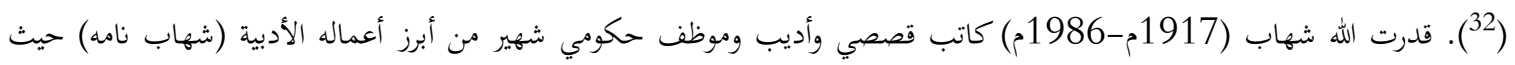

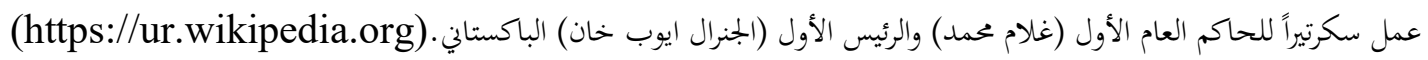

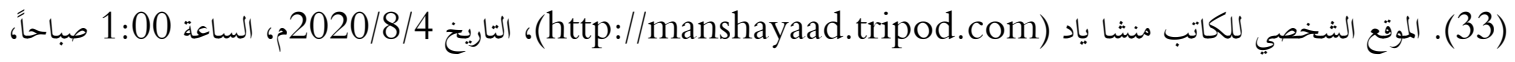
راولبندي، باكستان

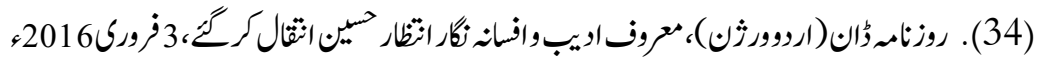

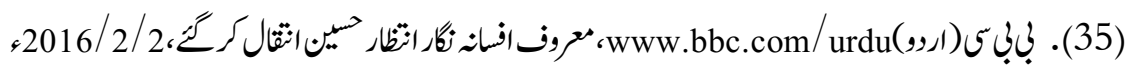

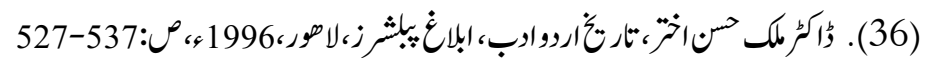

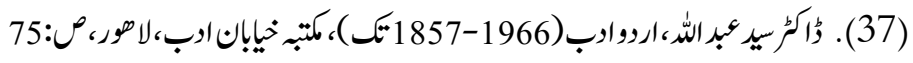

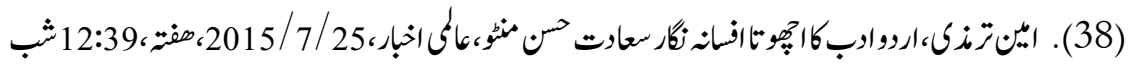

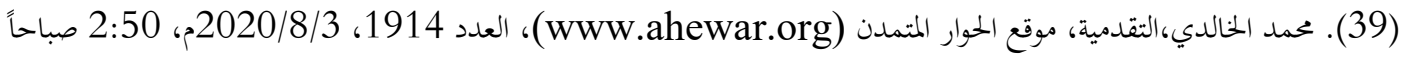

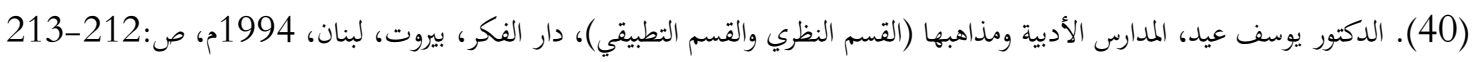

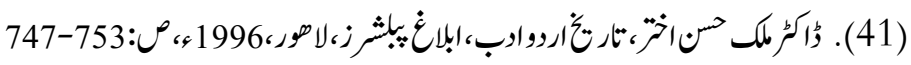


(12). شوكت ثَانوي (1904م-1963م) كاتب قصصي روائي مسرحي وشاعر ومذيع الذي ولد في مدينة بكوبال الهندية وتوفي في مدينة راولبندي الباكستانية حيث اشتهر أساسياً بسبب القصص والروايات والمسرحيات والمقالات الساخرة. (https://ur.wikipedia.org) (43). شفيق الرحمان (1920م-2000م) طبيب وكاتب قصصي ومترجم الذي ولد في مدينة كالانور الواقعة في البنجاب الهندية وتوفي في مدينة راولبندي الباكستانية حيث تتميز أعماله القصصية بمزيج من الرومانسية والسخرية. (https:/ur.wikipedia.org)

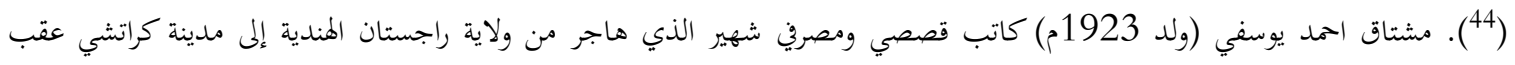

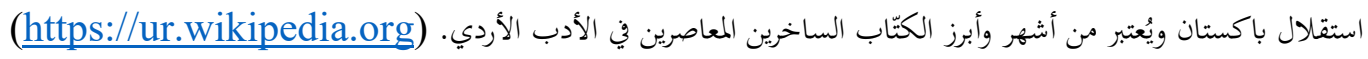

\section{(c) (7)}

This work is licensed under a Creative Commons Attribution 4.0 International License. 